\title{
THE PHONE MAKES US SCREAM: CORPUS STUDY OF ENGLISH AND RUSSIAN
}

\author{
JULIA KUZNETSOVA \\ University of Tromsø
}

\section{A B S T R ACT}

This study explores English and Russian speech verbs with phone prepositional phrases (PPs). It investigates two hypotheses: 1) A phone PP produces an independent construction and 2) A phone PP can be freely added to any speech verb. Two constructions in English and two constructions in Russian are used as the material for the analysis. In both languages I explore the most generally used phone PP and compare it with a PP meaning 'speak into the phone'. I present a new method - statistical profiling, that explores which words occur in a slot of a construction most frequently and how that frequency list for a slot is changed if another slot is filled. This paper shows that English on the phone phrase can freely be added to any speech and sound verb, while other phone PPs produce different phone constructions.

\section{[1] INTRODUCTION}

This study shows how one small and supposedly insignificant PP can completely change the distribution of the verbs used with it. I explore this question on the example of speech and sound verbs that can be used with phone PPs in English and Russian. In both languages I investigate the most generally used PPs (on the phone in English (1) and po telefonu 'speak on phone-DAT' in Russian (2)) and compare them with the PPs with preposition into (into the phone in English (3) and $v$ telefon 'into the phone-ACC' in Russian (4)). The structure and examples of those PPs are given in Table 1 on the following page. For the purposes of this paper I consider a verb to be a speech verb if it means a sound that can come out of a person's mouth. Hence, I explore verbs like breathe or sigh that are usually not considered to be speech verbs. Verbs that denote an act of communication such as say, speak or talk are referred to as neutral speech verbs and are opposed to the verbs that introduce some additional information about the character of communication such as English shout and whisper or Russian zagovorit' 'start talking'.

(1) It feels wrong to sit in my pajamas TALKING ON THE PHONE with a U.S. attorney in D.C., sounding tough about a criminal he's trying to put away. [Huston, James W. Marine One (2009)] 


\begin{tabular}{|l|l|}
\hline PP & Examples \\
\hline 1) on + NP & speak on the phone \\
\hline 2) into + NP & speak into the phone \\
\hline 3) po + NPdat & govorit' po telefonu 'speak on phone-DAT' \\
\hline 4) v + NPacc & $\begin{array}{l}\text { govorit' v telefon 'speak into phone-ACC' } \\
\text { govorit' v trubku 'speak into receiver-ACC' }\end{array}$ \\
\hline
\end{tabular}

TABLE 1: Phone PPs in Russian and English

(2) Prezident SŠA Buš 12 minut GOVORIL PO TELEFONU $\mathrm{s}$ president USA Bush 12 minutes talked on the-phone-DAT.SG with prem'er-ministrom Slovakii Mikulašem Dzurindoj. prime minister Slovakia Mikuláš Dzurinda 'President of USA Bush for 12 minutes TALKED ON THE PHONE with the prime minister of Slovakia Mikuláš Dzurinda.'

[Janina Sokolovskaja. Ljaščuk idët v Irak. Ukrainskie voennye gotovy $\mathrm{k}$ otpravke v Persidskij zaliv (2003) //«Izvestija», 2003.02.26]

(3) One guy called up and just SCREAMED INTO THE PHONE, no contaminated blood!

[One-Horned Unicorn Deer Found in Italy. The Bryant Park Project 8:009:00 AM. (2008)]

(4) Počemu ty togda ne skazala? - ZAKRIČAL ON V TRUBKU. why you then not say? - shouted he into receiver Why didn't you say it then? - SHOUTED HE INTO THE RECEIVER. [Olga Zueva. Skaži čto ja tebe nužna . . .// «Daša», Nr. 10, 2004]

It seems that almost any speech or sound verb can be used with phone PP. Such uses raise the interesting theoretical question of whether this PP can be freely added to any speech verb. On the one hand this PP is not always used when a speech verb is used: usually use of a verb like govorit' 'talk' does not imply speaking into a phone. This argument appears only if the situation described by the sentence is suitable, i.e. includes a phone. On the other hand when it does appear it is semantically connected to the speech verb - it describes the channel for the movement of sound. Thus it remains unclear whether this PP can be freely added to a speech verb or these are realizations of a special phone construction. These two hypotheses will be evaluated based on statistical profiling. 


\section{[2] STATISTICAL PROFILING}

Statistical profiling uses Construction Grammar (Fillmore 1989; Goldberg 1995, 2006; Tomasello 2003; Fried \& Boas 2005) as its theoretical background. Construction Grammar is a theoretical approach that aims to account for various language phenomena using constructions. A construction is a pairing of a form and a meaning; a construction consists of several elements and has semantic restrictions on them. This approach can be illustrated with the example of the there-construction discussed in a recent book by Kuno \& Takami (2004). Their study offers a constructional account for several phenomena in English that are usually considered to be connected with Unaccusativity. The authors show that the Construction Grammar approach gives better predictions about the data. For example Kuno \& Takami $(2004,58)$ propose the following list of functional restrictions on the there-construction: "The there-construction is acceptable to the extent that the string to the left of its logical subject is interpretable as denoting existence, absence, appearance, or non-appearance of the logical subject referent. In addition, when the construction has a presentational force, the existence, absence, appearance, or non-appearance that the construction represents must be observable to the speaker (or the person whose point of view the speaker is representing)."

These restrictions allow the authors to explain some uses of there-sentences that contradict the Unaccusativity approach. First, it becomes possible to explain why transitive verbs can be used in the there-construction, see (5). Even though the verb cross is transitive, cross someone's mind denotes an event of appearing. Second, it explains why there-sentences with some unaccusative verbs are not grammatical (6), however a slight change in the sentence makes them grammatical (7). Addition of a locative phrase transforms how the situation is observed. The locative phrase and the verb together serve to denote the existence of the referent. Third, it explains why sometimes a change in a grammatical form affects the grammaticality of a there-sentence, see (8). "[T] he progressive form, since it describes an on-going action or event, establishes the speaker as a spectator of the action or event, and this fact in turn contributes to the 'existence' interpretation of the string to the left of the logical subject." [ibid: 53].

(5) There crossed her mind a most horrible thought. (Kuno \& Takami 2004, 21b from Kayne (1979))

(6) *There smoldered a flag in a corner of the room. (Kuno \& Takami 2004, 22a)

(7) In a corner of the room there smoldered a flag that some angry patriot had torn down and ignited. (Kuno \& Takami 2004, 23a)

(8) a. *There swam in the river a young girl with a red headband.

(Kuno \& Takami 2004, 46b) 
b. There was swimming in the river a young girl with a red headband. (Kuno \& Takami 2004, 45b)

Thus we see that the constructional approach in the case of there-sentences has an explanatory advantage that the unaccusativity approach lacks.

In investigating a construction, the relevant questions are what is the form of the construction, what is the meaning of the construction and what semantic restrictions does a construction have on its slots. While the first two questions are often investigated in the literature on construction grammar, the issue of the semantic restrictions on a slot is less studied. However, the restrictions posed on the whole construction and on its elements are an important part of a construction, because without knowing what restrictions a construction has we cannot explain grammatical and ungrammatical uses of the construction. This paper offers an objective method to find such restrictions using statistical methods - statistical profiling.

Statistical profiling is not the first attempt to apply statistical methods in construction grammar. S. Gries and A. Stefanowitsch have developed a statistical approach called collostructional analysis, which measures the attraction and repulsion of a lexeme for a slot of a construction (Stefanowitsch \& Gries 2005, 2003; Gries \& Stefanowitsch 2004). For example, Stefanowitsch \& Gries (2005) discuss which lexemes are attracted and repulsed in the causative into-construction. Using the frequencies of two lexemes filling different slots in the construction (for example fool and thinking), they can predict what frequency their pairing would have if these events were independent. Comparing that prediction with the actual frequency of the pair, the authors make a conclusion about the attraction or repulsion of the two lexemes in the construction. Two lexemes are attracted if the actual frequency is higher than the prediction. Two lexemes are repelled if the actual frequency is lower than the prediction. For example, Stefanowitch \& Gries show that fool into thinking occurs much more frequently than fool into $V$-ing and $V$ into thinking would predict.

The semantics of some frames coincides with the semantics of the construction and elements of such frames are attracted to the construction, while some pairs of verbs do not constitute a suitable frame and as a result are repulsed from a construction. Tricking somebody into believing into something is a well formed idea in the mind of the speaker of English and therefore the instances of this frame such as fool into thinking or mislead into believing appear at the top Stefanowitch \& Gries' list of attracted lexemes. On the other hand, physical aggression is an ineffective way to change someone's mind, and as a result we see that items reflecting this frame such as force into thinking or bully into believing are repulsed from the construction. Thus a collostructional analysis uncovers the semantic structure of the examples of a construction. 
However collostructional analysis has several disadvantages. First, this method has a strong preference towards idiomatic use, for example in the of -construction the sure winner is cup of tea which definitely is an example of idiomatic use, and therefore does not provide much information about semantic restrictions on a slot. Second, the most frequent words such as do, talk or walk disappear from the list of attracted constructions, since they are usually not attracted to a construction with a specific meaning, such as for example causation. For instance, the verb talk is not in the list of the verbs attracted to a verbal slot of the $V$ on the phone construction. This is a minus because even though these frequent verbs are not attracted to a slot, among all examples of a construction they appear frequently due to their overall frequency. As we know from experimental studies conducted by Goldberg (2006), the items that appear in a slot frequently contribute to our understanding of a construction. The most frequent items appearing in a slot give us information about the most neutral possible filler for the slot, thus, cutting these verbs we lose important information about semantic restrictions on the slot.

Statistical profiling, like collostructional analysis, investigates correlations between lexical items occurring in two different slots of a grammatical construction. Yet, statistical profiling concentrated on finding semantic restrictions on a slot solves both problems mentioned above: it is not skewed toward idiomatic use, actually idioms never appear in the results of the statistical profiling, and statistical profiling does not exclude the most frequent items, it only measures if these items are repulsed from a slot of a construction. Statistical profiling of the construction is based on the idea that the distribution of the elements in the slot reflects the semantic requirement on that slot. This predicts that if the distribution of elements in slot ${ }_{1}$ is changed significantly when we fill slot ${ }_{2}$, we are dealing with an independent construction. To use this method we need to explore which words occur in a slot of a construction most frequently and how the frequency list for slot $_{1}$ is changed if slot $_{2}$ is filled.

For example, coming back to the phone PP used with speech verbs, statistical profiling predicts that the phone construction should have specific semantic requirements on its elements and particularly on the verb in it. As a result of the semantic requirement, the distribution of verbs possible in the construction has to be different (and the difference is statistically significant) from the distribution of those verbs in general in the corpus, i.e. after filling slot $_{2}$ with the phone the distribution of the verbs in slot $_{1}$ is changed. On the other hand if these PPs can be added freely to a speech verb, then the distribution of the verbs with the phone PP should be similar to the distribution of the verbs without the phone PP, i.e. filling $\operatorname{slot}_{2}$ with the phone does not affect distribution of elements in slot ${ }_{1}$. The case studies below show the use of this approach to the speech verbs with the phone PPs. For each of the phone PPs there will be a choice between two alternative hypotheses: 1) A phone PP produces an independent construction and 2) A 
phone PP can be freely added to any speech verb.

\section{[3] DATA}

English and Russian data for this study is collected from corpora. English data and examples for this study are collected from the Corpus of Contemporary American English $\left(\mathrm{CoCA}^{1}\right)$, which consists of 385 million words. Russian data and examples for this study are collected from the Russian National Corpus $\left(\mathrm{RNC}^{2}\right)$, which consists of 140 million words. Table 2 shows how many occurrences of each phone PP were found in the corpus. A speech verb that appears with a PP five or more than five times is included in the list of top speech verbs for that PP. Table 2 also shows how many top speech verbs are found for every phone PP. It can be seen that usually there are eight or nine top speech verbs for a PP, but the PP $v$ telefon 'into the phone' has noticeably less top speech verbs - only five. To make the data for the Russian PP v+NPacc more comparable with data for other phone PPs I explored an additional variant of this PP: $v$ trubku 'into the receiver', which has twelve top speech verbs.

\begin{tabular}{lrr}
\hline PP & All occurences & Top speech verbs \\
\hline on the phone & 7230 & 8 \\
into the phone & 507 & 9 \\
po telefonu 'on the phone' & 2049 & 9 \\
v telefon 'into the phone' & 193 & 5 \\
v trubku 'into the receiver' & 272 & 12
\end{tabular}

TABLE 2: Top speech verbs with phone PPs

\section{[3.1] On the phone}

This section applies statistical profiling to the speech verbs with phone PP on the phone. All verbs that appeared in the context of PP on the phone in the CoCA are collected (7230 examples). Table 3 on the next page shows the eight verbs that appeared more than four times in this small subcorpus. The column labeled coRPus shows how many examples of this verb are found in the corpus. The column labeled PREDICTED gives us the number of examples that would occur before the $\mathrm{PP}$, if that distribution were similar to the distribution in corpus. The column labeled OBSERVED shows how many examples of that verb are found in the context of PP on the phone. The numbers in the column PREDICTED are calculated using the following mechanism. The eight speech verbs are used most frequently with into

[1] http://www.americancorpus.org

[2] http://www.ruscorpora.ru 
the phone are taken (990 examples). The number of occurrences for the same verbs in the corpus is calculated (390 370 examples). For each verb the percentage of its occurrences in the corpus is calculated. For example, for the verb talk, which occurs in 256892 examples in the corpus, this percentage is $65 \%$, since 256892 is $65 \%$ of 390370 . Thus if the distribution with on the phone were the same as in the corpus it would occur in 651 examples (65\% of 990 examples), however it actually occurs in 741 examples, as can be seen from the column labeled OBSERVED.

\begin{tabular}{lrrr}
\hline VERB & CORPUS & $\begin{array}{r}\text { ON THE PHONE } \\
\text {-PREDICTED }\end{array}$ & $\begin{array}{r}\text { ON THE PHONE } \\
\text {-OBSERVED }\end{array}$ \\
\hline talk & 256829 & 651 & 741 \\
speak & 80590 & 205 & 140 \\
cry & 23139 & 59 & 33 \\
sound & 14929 & 38 & 29 \\
chat & 7594 & 19 & 26 \\
gab & 109 & 0 & 9 \\
whisper & 2714 & 7 & 6 \\
yell & 4466 & 11 & 6 \\
\hline TOTAL & 390370 & 990 & 990
\end{tabular}

TABLE 3: Top speech verbs with the PP on the phone

The semantic field of speech and sound in the CoCA is dominated by two verbs: talk and speak, as the left pie chart of Figure 1 on the following page shows. The same verbs dominate with phone PP on the phone, as can be seen from the right pie chart of Figure 1. The two charts in Figure 1 show that the distribution of the speech and sound verbs with on the phone is similar to the distribution of these verbs in the corpus. While the chi-square test shows that the difference is statistically significant ${ }^{3}\left(\chi^{2}=51.6,6 d_{f}, P=2 E-09\right)$, the effect size index ${ }^{4} w=0.22$ shows that the size of the effect is small. Thus the second hypothesis is confirmed: English on the phone phrases can attach freely to any speech verb. The most frequent speech verbs are frequent in this construction and vice versa. Therefore the PP on the phone does not add a lot of specific information and does not pose additional semantic requirements on the verbs used with it.

[3] For this test and all the tests below, both the chi-square test and the calculation of the effect size effect index $w$ are performed using only those verbs which have more than 5 predicted occurrences

[4] The effect size index $w$ for goodness-of-fit chi-square test is discussed in (Cohen 1988/1977), $w=0.1$ is considered small, $w=0.3$ medium and $w=0.5$ large effect size. Thus the effect size with the index $w=0.22$ can be characterized as medium to small. However, we will see below that the noticeable differences result in the effect size being higher than $w=0.5$, therefore the effect size with the index $w=0.22$ might be counted as insignificant. 

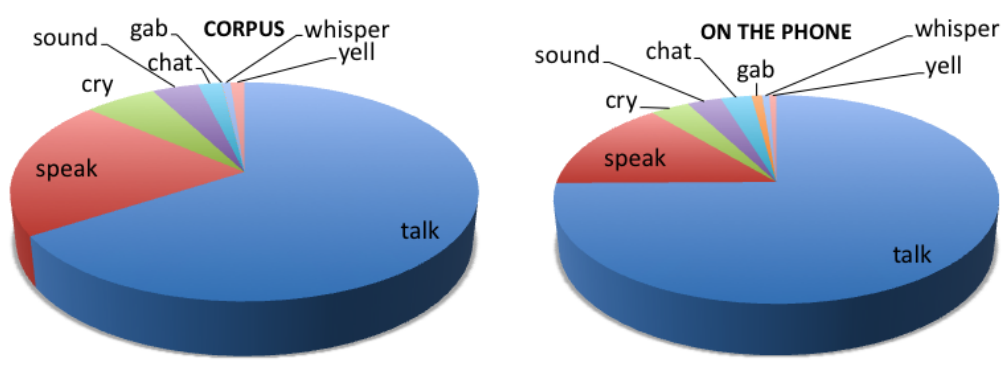

FIGURE 1: Top speech verbs with the PP on the phone

\section{[3.2] Into the phone}

If we look at a similar table for the PP into the phone, we see that the distribution in the corpus is as in the previous case dominated by neutral speech and sound verbs: say, speak and talk. Thus the distribution in the CoCA predicts that these verbs should dominate the distribution with the PP into the phone: the column labeled PREDICTION gives a prediction of 209 occurrences of say, thirteen occurrences of speak, thirty occurrences of talk and three or less occurrences of other verbs. However, the distribution of the top speech and sound verbs with PP into the phone is noticeably different. Neutral speech verbs such as say and talk appear less frequently than predicted, while verbs of shouting (scream, shout, yell, bark) and verbs of whispering (whisper, sigh, breathe) appear more frequently than the corpus predicts.

\begin{tabular}{lrrr}
\hline VERB & CORPUS & $\begin{array}{r}\text { INTO THE PHONE } \\
\text {-PREDICTED }\end{array}$ & $\begin{array}{r}\text { INTO THE PHONE } \\
\text {-OBSERVED }\end{array}$ \\
\hline say & 1845675 & 209 & 96 \\
speak & 112668 & 13 & 43 \\
scream & 21312 & 2 & 29 \\
whisper & 18640 & 2 & 22 \\
shout & 19045 & 2 & 19 \\
yell & 13531 & 2 & 18 \\
talk & 262293 & 30 & 17 \\
sigh & 13433 & 1 & 9 \\
breathe & 23673 & 3 & 7 \\
bark & 6675 & 1 & 5 \\
\hline TOTAL & 2336945 & 265 & 265
\end{tabular}

TABLE 4: Top speech verbs with the PP into the phone 
The differences between the pie chart on the left and on the right of Figure 2 show that the distribution of the speech and sound verbs with into the phone is different from the distribution of the same verbs in the corpus. This difference is statistically significant $\left(\chi^{2}=135.9,2 d_{f}, P=2 E-30\right)$, and the size of the effect is large $w=0.71$. Thus for this PP the first hypothesis is confirmed: it produces a special phone construction with specific semantic requirements on the verb that can be used in it.
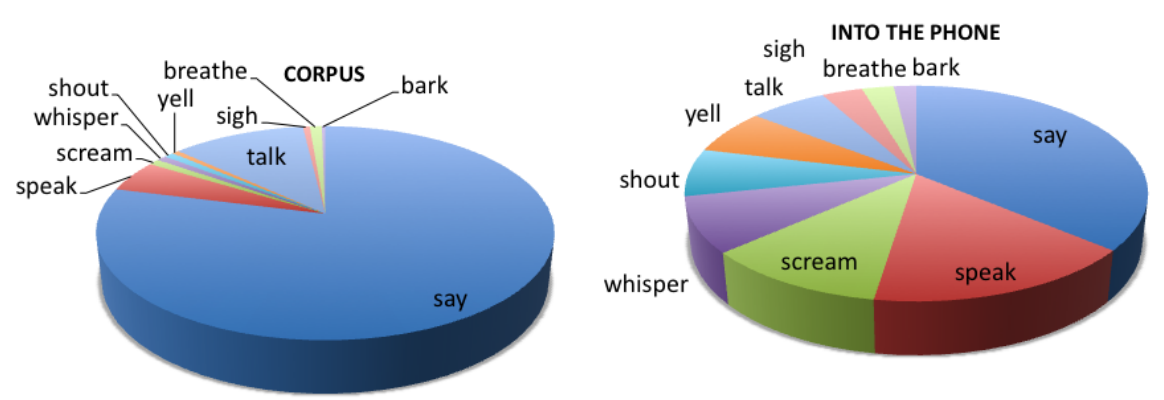

FIGURE 2: Top speech verbs with the PP into the phone

\section{[3.3] Po telefonu 'On the phone'}

If we turn to the Russian analogue of the English PP on the phone, we see that the top speech verbs with the PP po telefonu 'on the phone' mostly belong to the neutral speech verbs, see Table 5 on the following page. We have seen that in English the PP on the phone can freely be added to any speech and sound verbs. Here, the observed numbers of occurrences are noticeably different from what is predicted.

Figure 3 on page 357 shows that the distribution of the speech and sound verbs with po telefonu 'on the phone' is different from the distribution of the same verbs in the corpus. This difference is statistically significant $\left(\chi^{2}=1174.1,5 d_{f}, P=\right.$ $1 E-251$ ), and the size of the effect is tremendous $w=1.37$. The main difference is in the distribution of most neutral verbs govorit' 'talk' and skazat' 'say'. While the verb skazat' dominates in the corpus, the top verbs with with the PP po telefonu are dominated by govorit' 'talk'.

This difference is affected by punctuality vs. durativity of an event. The nature of the situation of speaking on the phone presupposes that the situation lasts over a period of time. As a result the verbs that denote protracted, "durative" events such as govorit' 'talk' are preferred by this PP, while instantaneous and "punctual" events such as skazat' 'say' are dispreferred. Because of this preference all imperfective speech verbs (govorit' 'talk', razgovarivat' 'converse', sprašivat' 'ask', boltat ' 'chatter', rasskazyvat' 'tell', orat' 'yell') are used with the PP po telefonu 'on 


\begin{tabular}{llrrr}
\hline VERB & GLOSS & CORPUS & $\begin{array}{r}\text { PO TELEFONU } \\
\text {-PREDICTED }\end{array}$ & $\begin{array}{r}\text { PO TELEFONU } \\
\text {-OBSERVED }\end{array}$ \\
\hline govorit' & talk & 44477 & 190 & 286 \\
razgovarivat' & converse & 4587 & 20 & 153 \\
skazat' & say & 76397 & 327 & 57 \\
pogovorit' & talk for a while & 6248 & 27 & 41 \\
sprašivat' & ask & 330 & 1 & 27 \\
boltat' & chatter & 920 & 4 & 25 \\
rasskazyvat' & tell & 6656 & 28 & 17 \\
vyzvat' & send for & 4224 & 18 & 7 \\
orat' & yell & 726 & 3 & 5 \\
\hline TOTAL & 144565 & 618 & 618 &
\end{tabular}

TABLE 5: Top speech verbs with the PP po telefonu 'on the phone'

the phone' more frequently than the corpus predicts. Between the two perfective verbs the verb pogovorit' 'talk for a while', which has a reference to the period of time added by the prefix po-is used more frequently than the corpus predicts and the only punctual perfective verb in the list skazat' 'say' is used less frequently than overall. Thus the PP po telefonu 'on the phone' produces a new independent phone construction sensitive to the durativity of the event.

\section{[3.4] V telefon 'into the phone' and $v$ trubku 'into the receiver'}

There are only five top speech verbs with PP $v$ telefon 'into the phone'. However even such a small list shows preferences similar to those we observed for its English analogue into the phone. While neutral speech verbs such as govorit' 'talk' and skazat' 'say' show a decrease compared to the prediction, shouting verbs such as kričat' 'shout' and orat' 'yell' occur with the PP $v$ telefon 'into the phone' more frequently than the corpus predicts.

\begin{tabular}{llrrr}
\hline VERB & GLOSS & CORPUS & PREDICTED & OBSERVED \\
\hline kričat' & shout & 28993 & 3 & 25 \\
govorit' & talk & 344097 & 30 & 17 \\
skazat' & say & 421203 & 37 & 16 \\
otvetit' & answer & 2836 & 0 & 7 \\
orat' & yell & 4983 & 1 & 6 \\
\hline TOTAL & 802112 & 71 & 71 &
\end{tabular}

TABLE 6: Top speech verbs with the PP $v$ telefon 'into the phone' 


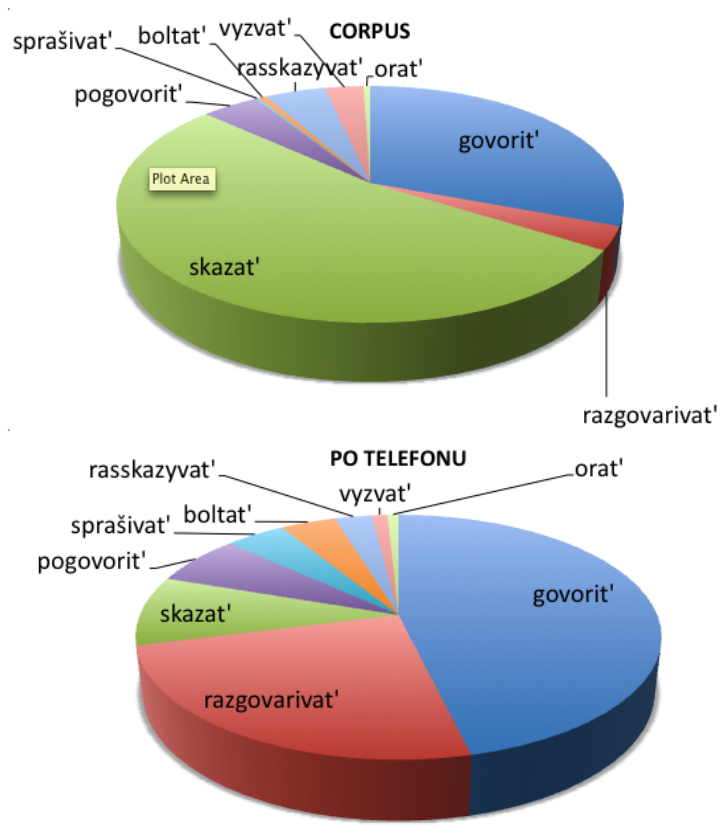

FIGURE 3: Top speech verbs with the PP po telefonu 'on the phone'

Even though the five top speech verbs give us some indications about the behavior of this phone PP, there is, as I mentioned above, not enough data for comparison. To make the data on the phone PP with the preposition $v$ more representable I investigate an additional example of that PP using trubka 'receiver' as a filler for the NP slot. The PP $v$ trubku 'into the receiver' has twelve top speech verbs, and clearly presents an expansion of the list of top speech verbs with the PP $v$ telefon 'into the phone'. Table 7 on the following page represents the speech verbs that occur with the PP $v$ trubku 'into the receiver' more than four times.

It can be seen from Table 7 that there are only eight different roots from which the twelve top speech verbs with the PP $v$ trubku 'into the receiver' are derived: burk- 'mutter', govor- 'talk', krik- 'shout', molk- 'remain silent', or- 'yell', otvet- 'answer', šept- 'whisper' and skaz- 'say'. Six verbs are produced using a bare verb root and verb ending and six other verbs are derived using a prefix or a suffix. Among the suffixes we see $z a-$ which has an ingressive meaning and is glossed as 'start V-ing' (see Sokolova (2009) and references therein) and pro- which has the meaning of producing a quantum and is glossed as ' $V$ something' (see Krongauz (1998) and references therein). The only suffix present in the data is -nu-, which has a semelfactive meaning (see Janda \& Makarova (2009) and references therein). However, as a speech verb its meaning is close to the quantum verbs: 


\begin{tabular}{llrrr}
\hline VERB & GLOSS & CORPUS & PREDICTION & OBSERVED \\
\hline kričat' & shout & 28993 & 6 & 69 \\
skazat' & say & 421203 & 89 & 36 \\
govorit' & talk & 344097 & 72 & 29 \\
zakričat' & start shouting & 13212 & 3 & 16 \\
otvečat' & answer & 110143 & 23 & 12 \\
prokričat' & shout something & 1488 & 0 & 10 \\
orat' & yell & 4983 & 1 & 7 \\
progovorit' & talk about something & 483 & 0 & 7 \\
prošeptat' & whisper something & 5047 & 1 & 6 \\
burknut' & mutter something & 1510 & 0 & 5 \\
zagovorit' & start talking & 13505 & 3 & 5 \\
molčat ${ }^{5}$ & remain silent & 40581 & 9 & 5 \\
\hline TOTAL & & 908245 & 207 & 207
\end{tabular}

TABLE 7: Top speech verbs with PP $v$ trubku 'into the receiver'

'mutter once' means 'mutter a quantum of information', so in section 4 examining the semantics of these verbs the verb burknut' 'mutter once' is grouped with the verbs that mean 'produce a quantum of information'.

The semantic field of speech and sound in the RNC is dominated by three verbs: govorit' 'talk', skazat' 'say' and otvečat' 'answer'. The first pie chart of Figure 4 on the next page shows those verbs which dominate the chart. In contrast, the environment of $v$ trubku 'into the receiver' is dominated by a different verb kričat' 'shout'. We can see from Figure 4 that kričat' 'shout' occurs with the PP $v$ trubku 'into the phone' ten times more often than the corpus predicts. The distribution in the corpus predicts that kričat' $v$ trubku 'shout into the reciever' should appear six times, while it is actually found in sixty-nine occurrences.

The two charts in Figure 4 clearly show that the distribution of the speech and sound verbs with 'into the phone' is different from the distribution of the same verbs in the corpus. This difference is statistically significant $\left(\chi^{2}=725.78,4 d_{f}, P=\right.$ $9 E-156$ ), and the effect size is gigantic $w=1.87$. Thus the first hypothesis is confirmed: these are examples of use of a specific phone construction with specific semantic requirements on the verb that can be used in it. The most frequent speech verbs are not frequent in this construction and the verbs that are most frequent in this construction are not frequent overall. We see that both Russian and English show tendency for shouting and whispering speech verbs, when the preposition meaning 'into' is involved in phone PP. The interesting question arises as to why these verbs are preferred by such PPs. 

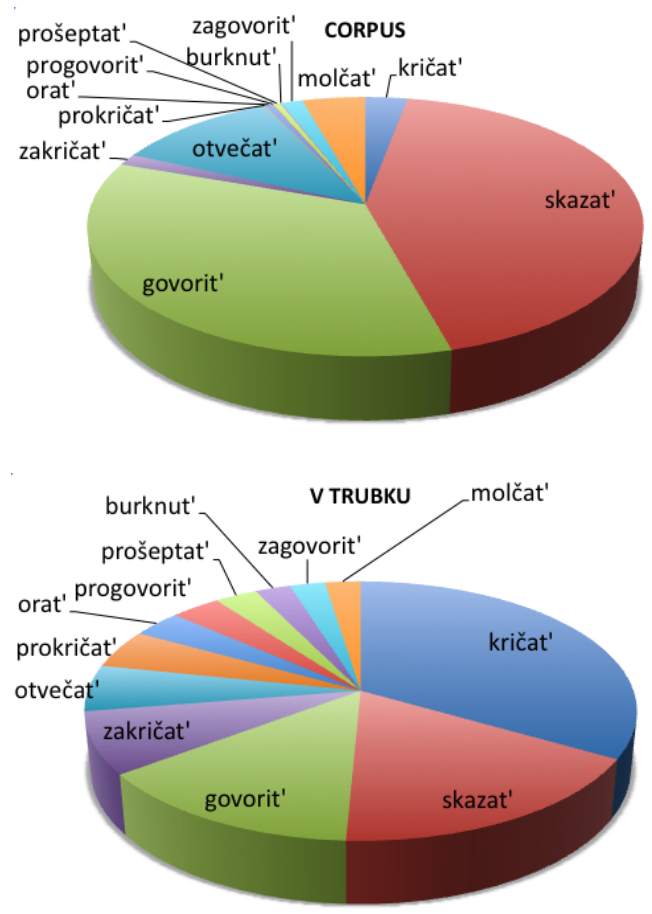

FIGURE 4: Top speech verbs with the PP $v$ trubku 'into the receiver'

[4] WHY DO WE SCREAM INTO THE PHONE?

Most neutral verbs from the list of the top speech verbs of the PP into the phonesay and talk - show a decrease compared to the prediction. Therefore, the PP into the phone repels neutral speech verbs, ${ }^{6}$ see Table 8.

\begin{tabular}{lrr}
\hline VERB & $\begin{array}{r}\text { INTO THE PHONE } \\
\text {-PREDICTED }\end{array}$ & $\begin{array}{r}\text { INTO THE PHONE } \\
\text {-OBSERVED }\end{array}$ \\
\hline say & 209 & 96 \\
speak & 13 & 43 \\
talk & 30 & 17
\end{tabular}

TABLE 8: Neutral verbs with the PP into the phone

Among the verbs that can be used with into the phone the most prominent items

[6] Yet, it is interesting, that the neutral speech verb speak occurs in this construction more frequently than the corpus predicts. The reason for that should be clarified in future studies. 
are non-neutral speech verbs: shouting verbs (like scream, shout, yell, bark, see Table 9) and whispering verbs (like whisper, sigh and breathe, see Table 10).

\begin{tabular}{lrr}
\hline VERB & $\begin{array}{r}\text { INTO THE PHONE } \\
\text {-PREDICTED }\end{array}$ & $\begin{array}{r}\text { INTO THE PHONE } \\
\text {-OBSERVED }\end{array}$ \\
\hline scream & 2 & 29 \\
shout & 2 & 19 \\
yell & 2 & 18 \\
bark & 1 & 5
\end{tabular}

TABLE 9: Shouting verbs with the PP into the phone

\begin{tabular}{lrr}
\hline VERB & INTO THE PHONE & INTO THE PHONE \\
& -PREDICTED & -OBSERVED \\
\hline whisper & 2 & 22 \\
sigh & 1 & 9 \\
breathe & 3 & 7
\end{tabular}

TABLE 10: Whispering verbs with the PP into the phone

For Russian, I have investigated in more details the PP $v$ trubku 'into the receiver', which has more top speech verbs and therefore gives us more material for comparison. Most neutral verbs from the list - skazat' 'talk', govorit' 'say', otvečat' 'answer' and molčat' 'remain silent' - show a decrease compared to the prediction. Therefore, the Russian PP $v$ trubku 'into the receiver' like its English analogue repels neutral speech verbs, see Table 11.

\begin{tabular}{llrr}
\hline VERB & GLOSS & PREDICTION & OBSERVED \\
\hline skazat' & say & 89 & 36 \\
govorit' & talk & 72 & 29 \\
otvečat' & answer & 23 & 12 \\
molčat' & remain silent & 9 & 5
\end{tabular}

TABLE 11: Neutral verbs with the PP $v$ trubku 'into the receiver'

Among the verbs that can be used with $v$ trubku 'into the receiver' the most prominent items are also non-neutral speech verbs: shouting verbs, whispering verbs and quantization verbs. Shouting verbs are presented by verbs like kričat' 'shout', zakričat' 'start shouting' or prokričat' 'shout something' and whispering 
verbs in Russian are presented by only one verb prošeptat' 'whisper something', see Table 12.

\begin{tabular}{llrr}
\hline VERB & GLOSS & PREDICTION & OBSERVED \\
\hline kričat' & shout & 6 & 69 \\
zakričat' & start shouting & 3 & 16 \\
prokričat' & shout something & 0 & 10 \\
orat' & yell & 1 & 7 \\
prošeptat' & whisper something & 1 & 6
\end{tabular}

TABLE 12: Shouting and whispering verbs with the PP $v$ trubku 'into the receiver'

Quantization verbs can be divided into two classes: first, verbs that mean to 'produce a quantum of information' (like progovorit' 'talk about something' or prošeptat' 'whisper something') and second, those that mean to 'start speaking' (like zakričat' 'start shouting' or zagovorit' "start talking'), see Table 13. Three verbs prokričat' 'shout something', zakričat' 'start shouting' and prošeptat' "whisper something' belong both in the shouting and whispering class and in the quantization class, and therefore appear both in Table 12 and Table 13. We are not able to see the class of quantization verbs in the English list of the top speech verbs with into the phone, because in Russian the quantization meaning is introduced by verbal prefixes and English lacks mechanisms parallel to Russian prefixation.

\begin{tabular}{llrr}
\hline VERB & GLOSS & PREDICTION & OBSERVED \\
\hline zakričat' & start shouting & 3 & 16 \\
prokričat' & shout something & 0 & 10 \\
progovorit' & talk about something & 0 & 7 \\
prošeptat' & whisper something & 1 & 6 \\
burknut' & mutter something & 0 & 5 \\
zagovorit' & start talking & 3 & 5
\end{tabular}

TABLE 13: Quantization verbs with the PP $v$ trubku 'into the receiver'

The preference for these verbs can be explained by the nature of the situation of talking into the phone. It is important to note that the person who utters a sentence like (9) is not a participant in the communication, but an observer. That person cannot be the destination point for the message said into the phone. On the contrary, this person is located near the participant who is the source of information in the communication into the phone and observes him or her speaking. 
V sosednem kupe poslyšalsja golos, KRIČAščIJ V TELEFON. in next compartment heard voice shouting into phone In the next compartment there was heard a voice SHOUTING INTO THE PHONE. [V.P. Kataev. Vremja, vpered! (1931-1932)]

There are three possibilities for the observer to participate in the communication. First, the speaker is talking to the listener, but the speaker is talking too loud and the observer hears it even though he or she might not be interested, as it happens in (9). This type of situation explains the raise in frequency for shouting verbs, such as shout or yell. Second, the speaker might be aware of the observer and intentionally might want to exclude the observer from the communication on the phone. In this case the speaker would speak in a low voice. This type of situation explains why whispering verbs occur frequently with PPs meaning 'into the phone'. Third, the speaker can participate in two communications at the same time: one with the listener on the phone and one with the observer. In this case it is not clear for whom the pronounced sentence is intended: for the speaker or for the observer. Thus such cases need disambiguation of the channel of communication. However, such disambiguation is not always necessary. If we are dealing with a continuing communication then channel disambiguation is not needed, but if the communication has just started or there has been produced a quantum of communication, then the channel needs to be chosen, because for this new piece of information the intended addressee is not clear. Thus when we use verbs like govorit' 'talk' or skazat' 'say', which refer to continuous communication, we do not need to mention if that was into the phone or not. However, if we use verbs like progovorit' 'talk about something' or zagovorit' 'start talking', which denote quantized communication, then we need to specify which channel was used for this communication. As a result, the verbs which mean 'start talking' or 'say a quantum' occur more frequently with PPs $v$ trubku 'into the receiver', which is a way to choose the channel.

Thus, the verbs attracted to the English into the phone and the Russian $v$ telefon 'into the phone' or $v$ trubku 'into the receiver' are shouting verbs, whispering verbs and quantization verbs. The preference for such verbs reflect the nature of the situation of communicating into the phone.

\section{[5] CONCLUSIONS}

Summing up it can be concluded that English on the phone can be added freely to any speech verb. Russian po telefonu, $v$ telefon ( $v$ trubku) and English into the phone cannot be added freely to a neutral speech verb and produce independent constructions. Russian po telefonu 'on the phone' has a preference for durative speech verbs. 'Into the phone' in both languages is used as an element of a phone construction that has a preference for shouting and whispering verbs both in Russian 
and English, and quantization verbs in Russian.

Statistical profiling used in this study explores the idea that if a slot is filled and that changes the distribution of elements in another slot significantly, then we are dealing with a new construction. Based on the construction grammar approaches, it can be assumed that significant change in the filling of a slot results from any restriction posed on that slot, therefore such change signals that we are facing a new construction that is characterized with new restrictions. Statistical profiling provides a measure of how far the construction has moved on the scale of the syntax vs. lexicon continuum (Croft 2001, 17). In addition it demonstrates what kind of restrictions on the variable the new construction has.

\section{ACKNOWLEDGEMENTS}

I would like to thank the anonymous reviewers, whose comments helped to improve this paper.

\section{REFERENCES}

Cohen, J. 1988/1977. Statistical power analysis for the behavioral sciences. New York: Academic Press.

Croft, W. 2001. Radical Construction Grammar: Syntactic Theory in Typological Perspective. Oxford: Oxford University Press.

Fillmore, C. J. 1989. Constructions. A Construction Grammar Approach to Argument Structure. In S. Axmaker, A. Jaisser \& H. Singmaster (eds.), Proceedings of the Fourteenth Annual Meeting of the Berkeley Linguistics Society, 35-55. University of California, Berkeley: Berkeley Linguistics Society.

Fried, M. \& H.C. Boas. 2005. Grammatical constructions: Back to the roots. Amsterdam/ Philadelphia: John Benjamins.

Goldberg, A. E. 1995. Constructions. A Construction Grammar Approach to Argument Structure. Chicago, IL: University of Chicago Press.

Goldberg, A. E. 2006. Constructions at Work: the nature of generalization in language. Oxford: Oxford University Press.

Gries, S. Th. \& A. Stefanowitsch. 2004. Co-varying collexemes in the intocausative. In M. Achard \& S. Kemmer (eds.), Language, Culture, and Mind, Stanford, CA: CSLI Publications.

Janda, L. A. \& A. Makarova. 2009. Do It Once: A Case Study of the Russian HySemelfactives. Scando-Slavica 66. 78-99. 
Kayne, R. 1979. Rightward NP movement in French and English. Linguistic Inquiry 10. 710-719.

Krongauz, M.A. 1998. Pristavki i glagoly v russkom jazyke: semantičeskaja grammatika. Moscow: Jazyki russkoj kul'tury.

Kuno, S. \& K. Takami. 2004. Functional Constraints in Grammar. On the unergativeunaccusative distinction. Amsterdam/Philadelphia: John Benjamins.

Sokolova, S. 2009. Ingressive usage of the Russian verbal prefixes za- and po-: Any spatial features? In Workshop on Spatial Expressions, University of Tromsø. May 2009.

Stefanowitsch, A. \& S. Th. Gries. 2003. Collostructions: investigating the interaction between words and constructions. International Journal of Corpus Linguistics 8(2). 209-243.

Stefanowitsch, A. \& S. Th. Gries. 2005. Covarying collexemes. Corpus Linguistics and Linguistic Theory 1(1). 1-43.

Tomasello, M. 2003. Constructing a language: a usage based theory of language acquisition. Cambridge: Harvard University Press.

AUTHOR CONTACT INFORMATION

Julia Kuznetsova

University of Tromsø

Department of Language and Linguistics

NO-9037 Tromsø

Norway

julia.kuznetsova@uit.no 